\title{
Frequency and clinical determinants of dementia after ischemic stroke
}

\author{
D.W. Desmond, PhD; J.T. Moroney, MD, MRCPI; M.C. Paik, PhD; M. Sano, PhD; J.P. Mohr, MD; \\ S. Aboumatar, MD; C.-L. Tseng, MPH; S. Chan, MD; J.B.W. Williams, DSW; R.H. Remien, PhD; \\ W.A. Hauser, MD; and Y. Stern, PhD
}

\begin{abstract}
Article abstract-Objective: To investigate the frequency and clinical determinants of dementia after ischemic stroke. Methods: The authors administered neurologic, neuropsychological, and functional assessments to 453 patients (age $72.0 \pm 8.3$ years) 3 months after ischemic stroke. They diagnosed dementia using modified Diagnostic and Statistical Manual of Mental Disorders, 3rd ed., revised criteria requiring deficits in memory and two or more additional cognitive domains as well as functional impairment. Results: The authors diagnosed dementia in 119 of the 453 patients (26.3\%). Regarding dementia subtypes, 68 of the 119 patients $(57.1 \%)$ were diagnosed with vascular dementia, 46 patients $(38.7 \%)$ were diagnosed with $\mathrm{AD}$ with concomitant stroke, and 5 patients $(4.2 \%)$ had dementia for other reasons. Logistic regression suggested that dementia was associated with a major hemispheral stroke syndrome (OR 3.0), left hemisphere (OR 2.1) and right hemisphere (OR 1.8) infarct locations versus brainstem/cerebellar locations, infarcts in the pooled anterior and posterior cerebral artery territories versus infarcts in other vascular territories (OR 1.7), diabetes mellitus (OR 1.8), prior stroke (OR 1.7), age 80 years or older (OR 12.7) and 70 to 79 years (OR 3.9) versus 60 to 69 years, 8 or fewer years of education (OR 4.1) and 9 to 12 years of education (OR 3.0) versus 13 or more years of education, black race (OR 2.6) and Hispanic ethnicity (OR 3.1) versus white race, and northern Manhattan residence (OR 1.6). Conclusions: Dementia is frequent after ischemic stroke, occurring in one-fourth of the elderly patients in the authors' cohort. The clinical determinants of dementia include the location and severity of the presenting stroke, vascular risk factors such as diabetes mellitus and prior stroke, and host characteristics such as older age, fewer years of education, and nonwhite race/ethnicity. The results also suggest that concomitant $\mathrm{AD}$ plays an etiologic role in approximately one-third of cases of dementia after stroke. Key words: Stroke—Cerebrovascular disease—Dementia-Vascular dementia—AD.
\end{abstract}

NEUROLOGY 2000;54:1124-1131

As a primary risk factor for dementia as well as a leading cause of disability and mortality in the United States, stroke can be considered to be a major public health problem. Our understanding of cerebrovascular disease as a basis for dementia has evolved during the last century, with an early focus on arteriosclerotic disease of the small vessels as a cause of cerebral atrophy and cognitive decline, ${ }^{1,2}$ shifting to an emphasis on the cumulative volume of cerebral infarction, ${ }^{3}$ and then to the multiplicity of infarcts and the concept of "multi-infarct dementia." Recent studies suggest that dementia after stroke is a function of a more complex group of determinants, including infarct characteristics, vascular risk factors, and host features. ${ }^{5,6}$ In addition, parallel research efforts into cerebrovascular disease and $\mathrm{AD}$ as bases for dementia have begun to intersect. Pathologic studies have found that those diseases frequently coexist ${ }^{7,8}$ and that concomitant cerebrovascular disease helps to determine the severity of dementia among patients with $\mathrm{AD},{ }^{9,10}$ suggesting that "mixed" dementia may be more common than previously recognized.

From 1988 to 1990, we recruited and examined a large cohort of ischemic stroke patients and recognized a high frequency ${ }^{11}$ and a heterogeneous group of clinical determinants ${ }^{5}$ of dementia, as noted earlier. From 1994 to 1997, we recruited a second large cohort of patients to confirm the earlier findings and identify additional clinical determinants. Here we present our findings based on our pooled cohort of 453 patients, the largest that has thus far been reported with comprehensive clinical assessments.

Subjects and methods. Subjects. As part of a prospective study of stroke and dementia, we recruited 585 subjects among patients consecutively admitted to Columbia-

From the Departments of Neurology and Pathology (Dr. Desmond), SUNY Downstate Medical Center, Brooklyn; and the Departments of Neurology (Drs. Moroney, Sano, Mohr, Aboumatar, Hauser, and Stern), Biostatistics (Dr. Paik and Ms. Tseng), Psychiatry (Drs. Sano, Williams, Remien, and Stern), and Radiology (Dr. Chan), and the Gertrude H. Sergievsky Center (Drs. Moroney, Sano, Hauser, and Stern), Columbia University, College of Physicians and Surgeons, New York, NY.

Supported by grants R01-NS26179, P01-AG07232, and K08-NS02051 from the National Institutes of Health.

Presented in part at the 51st annual meeting of the American Academy of Neurology; Toronto, Ontario, Canada; April 22, 1999.

Received June 25, 1999. Accepted in final form November 8, 1999.

Address correspondence and reprint requests to Dr. Desmond, SUNY Downstate Medical Center, 450 Clarkson Ave., Box 25, Brooklyn, NY 11203-2098; e-mail: dwdesmond@usa.net 
Presbyterian Medical Center for ischemic stroke. We recruited 297 of those patients from 1988 to 1990 and the remaining 288 patients from 1994 to 1997 . Eligibility requirements included an age of 60 years or older and a diagnosis of ischemic stroke within the previous 30 days confirmed by brain imaging (relevant infarct or normal). Patients were permitted to be of either sex and any race or ethnicity and patients with a history of prior stroke were eligible for inclusion. Patients were excluded when certain clinical features precluded a reliable assessment of cognitive function, including a Boston Diagnostic Aphasia Examination $^{12}$ severity rating $<3$, persistent impairment of consciousness, or a primary language other than English or Spanish. Additional exclusion criteria included the presence of a concomitant neurologic disorder potentially affecting cognitive function (e.g., PD) or a severe comorbid medical illness (e.g., terminal cancer) that would preclude follow-up throughout the 5-year duration of this prospective study. Patients were not excluded if a premorbid history of functional impairment suggested that they might have concomitant $\mathrm{AD}$. A more detailed description of our inclusion criteria and assessment methods is available in another publication. ${ }^{11}$

This study was approved by the Institutional Review Board of Columbia-Presbyterian Medical Center, and all subjects provided informed consent.

Assessment procedures. We performed our initial assessments, not including dementia diagnosis, 7 to 10 days after stroke. At that time, patients were administered the Mini-Mental State Examination (MMSE) ${ }^{13}$ and the Barthel Index, ${ }^{14}$ which taps the physical aspects of activities of daily living. Knowledgeable informants were administered the Blessed Functional Activity Scale (BFAS), ${ }^{15}$ which taps the cognitive aspects of activities of daily living, with a focus on patients' prestroke functional capabilities. Information regarding the presence or absence of prestroke functional impairment derived from that initial administration of the BFAS was used in the determination of the dementia subtype among patients meeting operationalized criteria for dementia, whereas subsequent administrations of the BFAS focused solely on patients' functional capabilities at the time of the examination. Regarding other assessments that were performed 7 to 10 days after stroke, neurologists specializing in stroke administered a structured neurologic examination and documented any history of stroke, TIA, or exposure to risk factors for cerebrovascular disease based on review of medical records and a structured interview administered to all patients and knowledgeable informants. Patients also were rated on the Stroke Data Bank Stroke Severity Scale, ${ }^{16}$ and a comprehensive medical history was recorded. Based on the review of clinical features and brain imaging performed immediately after stroke, patients were classified by infarct location and stroke syndrome using a modification of the methods of the Stroke Data Bank. Classifications of stroke location and syndrome were made independently of the neuropsychological test results. Three months after stroke, patients were administered a comprehensive neuropsychological evaluation and the Hamilton Depression Rating Scale (HDRS), ${ }^{17}$ and the MMSE, the Barthel Index, the BFAS, the neurologic examination, and the Stroke Severity Scale were repeated.
Neuropsychological evaluation. Cognitive testing was performed in either English or Spanish, based on the language spoken in the subject's home. We administered a battery of neuropsychological tests developed for use in epidemiologic studies of dementia to all subjects. ${ }^{18}$ This battery included measures of verbal and nonverbal memory (the Selective Reminding Test and a multiple-choice recognition version of the Benton Visual Retention Test), orientation (the MMSE orientation subtest), language (a 15-item version of the Boston Naming Test, letter and category fluency tests, and selected items drawn from the repetition and complex ideation subtests of the Boston Diagnostic Aphasia Examination), visuospatial function (the Rosen Drawing Test and a multiple-choice matching version of the Benton Visual Retention Test), verbal and nonverbal abstract reasoning skills (the Similarities subtest of the Wechsler Adult Intelligence Scale-Revised and the Identities and Oddities subtest of the Mattis Dementia Rating Scale), and attention (cancellation tasks using shapes and letters as targets).

Diagnostic paradigm. Dementia was diagnosed based on criteria modified from the Diagnostic and Statistical Manual of Mental Disorders, 3rd ed., revised (DSM-III-R) ${ }^{19}$ and consistent with criteria later proposed by the International Workshop of the National Institute of Neurological Disorders and Stroke-Association Internationale pour la Recherche et l'Enseignement en Neurosciences (NINDSAIREN). ${ }^{20}$ We required deficits in memory and two or more additional cognitive domains as determined in the neuropsychological evaluation as well as functional impairment not solely related to physical disability documented with the Blessed Functional Activity Scale. When patients were aphasic, we required that they exhibit evidence of nonverbal memory impairment. We defined impairment within any cognitive domain as any neuropsychological test score within that domain falling below a predetermined cutoff that was selected in a pilot study. We consider those cutoffs to be conservative. A pilot study found that interrater agreement on the diagnosis of dementia was excellent, with a kappa of 0.96 based on independent judgments made in a sample of 63 patients.

Clinical subtypes of dementia were defined based on the temporal association between the onset of the dementia syndrome and stroke as well as correlations between clinical and neuropsychological features. Essentially, vascular dementia was defined as the new onset of dementia after stroke, whereas $\mathrm{AD}$ with stroke was diagnosed when functional impairment preceded the index stroke based on the best historical information. Other potential explanations for a diagnosis of dementia included alcohol abuse and depression. Diagnostic agreement on the dementia subtype was found to be excellent based on the same sample of 63 patients, with a kappa of 0.79 .

Statistical analyses. To determine whether any selection bias might have resulted from our failure to examine a subset of patients 3 months after stroke, chi-square analyses were performed to compare the patients who were not examined with the patients who were examined with regard to the location and severity of the presenting stroke, vascular risk factors, and demographic variables. We then performed a logistic regression analysis to determine whether any of the variables found to be related to the failure to be examined 3 months after stroke in the univar- 


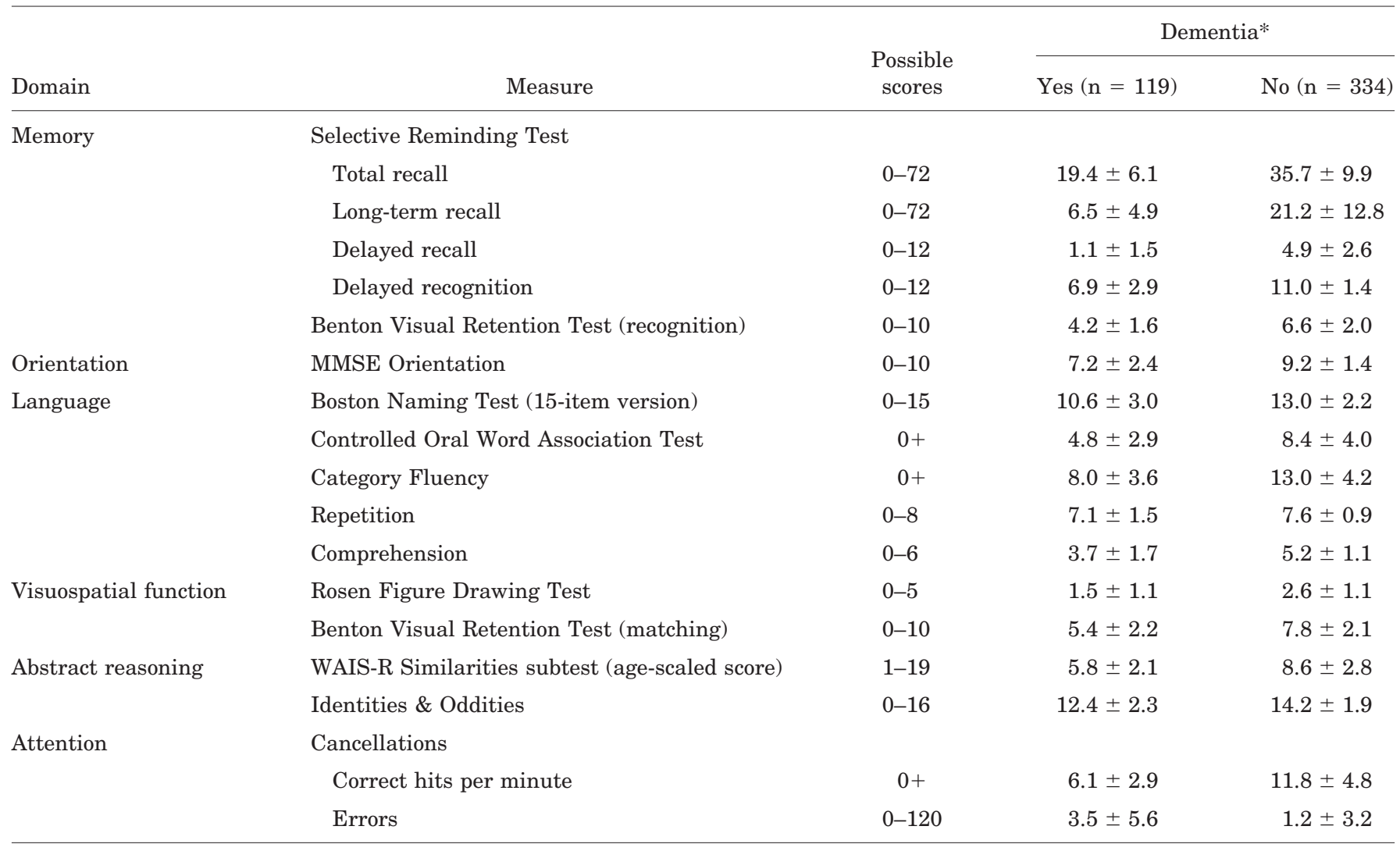

* Values are means $\pm \mathrm{SD}$. All between-group differences are significant at $p<0.001$ by $t$-test.

MMSE = Mini-Mental State Examination; WAIS-R = Wechsler Adult Intelligence Scale-Revised.

iate analyses $(p<0.10)$ would be independently related to the failure to be examined.

To investigate the clinical correlates of dementia, we performed chi-square analyses to compare the pooled group of patients who met criteria for dementia to those who did not meet criteria for dementia with regard to the clinical variables summarized above. We next performed a logistic regression analysis to determine whether any of the variables found to be relevant in the univariate analyses would be independently related to dementia status. We then entered depression, operationally defined as a total score $>11$ and the acknowledgment of depressed mood of any severity on the HDRS administered 3 months after stroke; aphasia; and a variable representing the recruitment cohort into that final model as covariates to adjust for any confounding effects. In addition, we explored potential interactions between each of the relevant clinical variables and each of the primary demographic variables. Finally, we performed the same set of analyses based solely on patients diagnosed with vascular dementia and nondemented stroke patients, excluding patients with $\mathrm{AD}$ with stroke and dementia resulting from other nonvascular etiologies, to investigate the clinical determinants of vascular dementia.

Results. Clinical characteristics of patients lost to followup. Of the 585 patients who were initially enrolled in our study, 453 patients $(77.4 \%$; age $72.0 \pm 8.3$ years) were examined 3 months after ischemic stroke. Of the 132 pa- tients who were not examined, 26 patients had died, 23 patients were medically ill or too severely impaired neurologically to be assessed, and 83 patients refused follow-up, had moved, or had been lost to follow-up. Thus, of the 536 patients who could have been examined, 453 (84.5\%) were examined. Patients who were not examined 3 months after stroke were significantly more impaired than patients who were examined on the MMSE $(20.5 \pm 6.1$ versus $23.2 \pm$ $5.3)$, the Barthel Index (59.4 \pm 31.8 versus $69.7 \pm 28.3)$, and the Stroke Severity Scale $(7.6 \pm 3.0$ versus $6.6 \pm 3.1)$ administered 7 to 10 days after stroke. Chi-square analyses suggested that the failure to be examined 3 months after stroke was associated with a major hemispheral stroke syndrome, the mechanism of the index stroke, a history of myocardial infarction, congestive heart failure, atrial fibrillation, age, and education. Logistic regression suggested that the failure to be examined was independently associated with a major hemispheral stroke syndrome (OR 2.20; 95\% CI 1.38 to 3.53 ), a history of myocardial infarction (OR 1.49; CI 0.89 to 2.48), congestive heart failure (OR 1.99; CI 1.11 to 3.56), age 80 years or older (OR 1.79; CI 1.03 to 3.11) and 70 to 79 years (OR 1.51; CI 0.94 to 2.42 ) versus 60 to 69 years, and 8 or fewer years of education versus 9 or more years of education (OR 1.66; CI 1.09 to 2.51).

Frequency and subtypes of dementia after ischemic stroke. Of the 453 patients who were examined 3 months after ischemic stroke, 119 patients met criteria for dementia (26.3\%; CI $22.2 \%$ to $30.3 \%$ ). Among the 119 stroke 
Table 2 Demographic variables by dementia status

\begin{tabular}{|c|c|c|c|}
\hline \multirow[b]{2}{*}{ Variable } & \multicolumn{2}{|c|}{ Dementia* } & \multirow[b]{2}{*}{$p$ Value } \\
\hline & $\begin{array}{c}\text { Yes } \\
(\mathrm{n}=119)\end{array}$ & $\begin{array}{c}\text { No } \\
(\mathrm{n}=334)\end{array}$ & \\
\hline \multicolumn{4}{|l|}{ Age } \\
\hline$\geq 80 \mathrm{y}$ & $41(34.5)$ & $42(12.6)$ & \multirow{3}{*}{$<0.001$} \\
\hline $70-79$ y & $48(40.3)$ & $115(34.4)$ & \\
\hline $60-69$ y & $30(25.2)$ & $177(53.0)$ & \\
\hline \multicolumn{4}{|l|}{ Education } \\
\hline $0-8$ y & $59(49.6)$ & $106(31.7)$ & \multirow[t]{3}{*}{$<0.001$} \\
\hline $9-12 y$ & $48(40.3)$ & $134(40.1)$ & \\
\hline$\geq 13 \mathrm{y}$ & $12(10.1)$ & $94(28.1)$ & \\
\hline \multicolumn{4}{|l|}{ Race/ethnicity } \\
\hline Black & $46(39.3)$ & $126(38.4)$ & \multirow[t]{3}{*}{0.003} \\
\hline Hispanic & $51(43.6)$ & $98(29.9)$ & \\
\hline White & $20(17.1)$ & $104(31.7)$ & \\
\hline Sex (male) & $48(40.3)$ & $167(50.0)$ & 0.070 \\
\hline Predominant language (English) & $63(53.4)$ & $217(65.0)$ & 0.026 \\
\hline Occupation (unskilled vs other) & $77(65.8)$ & $170(50.9)$ & 0.005 \\
\hline Handedness (right) & $110(98.2)$ & $299(91.2)$ & 0.012 \\
\hline Residence (northern Manhattan) & $64(53.8)$ & $149(44.6)$ & 0.085 \\
\hline
\end{tabular}

patients who met dementia criteria, 68 of the 119 patients (57.1\%) were diagnosed with vascular dementia, 46 patients $(38.7 \%)$ were diagnosed with "mixed" dementia (i.e., $\mathrm{AD}$ with stroke), and 5 patients $(4.2 \%)$ had dementia for other reasons.

Performance in neuropsychological testing performed 3 months after stroke stratified by dementia status is presented in table 1. Although it is not surprising that stroke patients with dementia were significantly more impaired than nondemented patients on all neuropsychological measures because the diagnosis of dementia was based on performance on those neuropsychological measures as well as the BFAS, note that stroke patients with dementia also were significantly more impaired than nondemented patients on the MMSE $(19.0 \pm 6.1$ versus $26.2 \pm 3.5$, with $77.4 \%$ versus $20.6 \%$ receiving a total score $<24$ ), the Barthel Index $(64.1 \pm 34.0$ versus $90.3 \pm 18.1)$, and the Stroke Severity Scale $(7.7 \pm 2.8$ versus $4.6 \pm 3.1)$. Stroke patients with dementia also received significantly higher total scores on the HDRS than nondemented patients $(6.8 \pm 5.7$ versus $4.3 \pm 4.3$, with $18.0 \%$ versus $6.9 \%$ receiving a total score $>11$ and acknowledging depressed mood).

Clinical determinants of dementia 3 months after ischemic stroke. Demographic characteristics, vascular risk factors, and features of the presenting stroke stratified by dementia status are shown in tables 2,3 , and 4 , respectively. Chi-square analyses suggested that dementia was associated with age, education, race/ethnicity, sex, predominant language, occupation, and residence. Handedness also was related to dementia status, with right-handed
Table 3 Vascular risk factors by dementia status

\begin{tabular}{lccc}
\hline & \multicolumn{2}{c}{ Dementia* } & \\
\cline { 2 - 3 } Variable & Yes & No & $p$ \\
Hypertension & $\mathrm{n}=119)$ & $(\mathrm{n}=334)$ & Value \\
Diabetes mellitus & $85(72.0)$ & $246(73.7)$ & 0.733 \\
Myocardial infarction & $49(41.2)$ & $107(32.0)$ & 0.072 \\
Angina & $16(13.8)$ & $57(17.1)$ & 0.410 \\
Atrial fibrillation & $28(24.3)$ & $70(21.1)$ & 0.466 \\
Congestive heart failure & $12(10.1)$ & $46(13.9)$ & 0.292 \\
Hypercholesterolemia & $14(11.9)$ & $31(9.4)$ & 0.438 \\
Consistent cigarette use & $24(20.9)$ & $80(24.2)$ & 0.471 \\
Consistent alcohol use & $61(51.7)$ & $201(60.9)$ & 0.081 \\
Prior stroke & $53(44.9)$ & $169(51.4)$ & 0.229 \\
Prior transient ischemic attack & $16(13.9)$ & $57(17.3)$ & 0.402 \\
\hline
\end{tabular}

* Values are frequencies (within-group percentages). Significance levels are based on chi-square analyses. Some within-group percentages are based on an incomplete sample due to small amounts of missing data.

patients at greater risk, but small cell sizes precluded our ability to enter it into the logistic regression analysis. Among vascular risk factors, dementia was associated with only diabetes mellitus and a history of prior stroke. Among features of the presenting stroke, dementia was associated with more severe hemispheral stroke syndromes, stroke location, and vascular territory.

As shown in table 5 (Model A), logistic regression suggested that dementia was associated with a major hemispheral stroke syndrome, reflecting the severity of neurologic impairment; left hemisphere and right hemisphere infarct locations versus brainstem/cerebellar infarct locations; infarcts in the pooled anterior and posterior cerebral artery territories versus infarcts in other vascular territories; diabetes mellitus; a history of prior stroke; age 80 years and older and 70 to 79 years versus 60 to 69 years; 8 or fewer years of education and 9 to 12 years of education versus 13 or more years of education; black race and Hispanic ethnicity versus white race; and residence in northern Manhattan. Depression was associated with dementia when it was entered into the final logistic model as a covariate (OR 3.58; CI 1.59 to 8.10), but the model was otherwise essentially unchanged. Aphasia and a variable representing the recruitment cohort were not significantly related to dementia status when they were entered into the final logistic model. No interaction terms were significantly related to dementia status.

The final logistic model was essentially unchanged when the analysis was restricted to patients with vascular dementia and nondemented patients, although the odds ratios increased for all vascular variables and decreased for the older age groups (table 5, model B). Atherothrombotic and lacunar stroke mechanisms were related to dementia in this model, however, whereas northern Manhattan residence was not. Depression was associated with dementia when it was entered into the final logistic model as a covariate (OR 3.31; CI 1.26 to 8.73), but the model was otherwise essentially unchanged. Aphasia and 
Table 4 Stroke characteristics by dementia status

\begin{tabular}{|c|c|c|c|}
\hline \multirow[b]{2}{*}{ Variable } & \multicolumn{2}{|c|}{ Dementia* } & \multirow[b]{2}{*}{$\begin{array}{c}p \\
\text { Value }\end{array}$} \\
\hline & $\begin{array}{c}\text { Yes } \\
(\mathrm{n}=119)\end{array}$ & $\begin{array}{c}\text { No } \\
(\mathrm{n}=334)\end{array}$ & \\
\hline \multicolumn{4}{|l|}{ Stroke syndrome } \\
\hline Major dominant hemispheral & $14(11.8)$ & $20(6.0)$ & 0.003 \\
\hline $\begin{array}{l}\text { Major nondominant } \\
\text { hemispheral }\end{array}$ & $19(16.0)$ & $23(6.9)$ & \\
\hline Minor dominant hemispheral & $11(9.2)$ & $48(14.4)$ & \\
\hline $\begin{array}{l}\text { Minor nondominant } \\
\text { hemispheral }\end{array}$ & $16(13.4)$ & $49(14.7)$ & \\
\hline Lacunar/deep hemispheral & $44(37.0)$ & $120(35.9)$ & \\
\hline Brainstem/cerebellar & $15(12.6)$ & $74(22.2)$ & \\
\hline \multicolumn{4}{|l|}{ Stroke location } \\
\hline Left hemisphere & $48(40.3)$ & $102(30.6)$ & 0.009 \\
\hline Right hemisphere & 49 (41.2) & $121(36.3)$ & \\
\hline Brainstem/cerebellum & $22(18.5)$ & $110(33.0)$ & \\
\hline \multicolumn{4}{|l|}{ Vascular territory } \\
\hline Internal carotid artery & $6(5.0)$ & $13(3.9)$ & 0.015 \\
\hline Anterior cerebral artery & $8(6.7)$ & $8(2.4)$ & \\
\hline Middle cerebral artery & $63(52.9)$ & $160(47.9)$ & \\
\hline Posterior cerebral artery & $20(16.8)$ & $44(13.2)$ & \\
\hline Vertebrobasilar & $22(18.5)$ & $109(32.6)$ & \\
\hline \multicolumn{4}{|l|}{ Stroke mechanism } \\
\hline Large artery atherosclerosis & $28(23.5)$ & $60(18.0)$ & 0.443 \\
\hline Cardiac embolism & $18(15.1)$ & $68(20.4)$ & \\
\hline Lacunar & $44(37.0)$ & $126(37.7)$ & \\
\hline Unknown/other cause & $29(24.4)$ & $80(24.0)$ & \\
\hline
\end{tabular}

* Values are frequencies (within-group percentages). Significance levels are based on chi-square analyses. Some within-group percentages are based on an incomplete sample due to small amounts of missing data.

the cohort variable were not significantly related to dementia status. Among potential interaction terms, only the interaction of sex and a major hemispheral stroke syndrome was related to dementia status (OR 5.44; CI 1.15 to 25.65), with women with a major hemispheral stroke syndrome at disproportionately increased risk of vascular dementia.

Discussion. The results of our study suggest that dementia is frequent after ischemic stroke, occurring in one-fourth of the members of our elderly cohort. Given that patients who were recruited but did not undergo the 3-month poststroke dementia assessment had experienced more severe hemispheral stroke syndromes, tended to be older and less well educated, and exhibited significantly greater cognitive and functional impairment 7 to 10 days after stroke than patients who were examined, however, it is likely that our study underestimated the true frequency of dementia after stroke, as we suggested in previous work. ${ }^{21}$ Among the 119 stroke patients who met dementia criteria, most were diagnosed with vascular dementia, whereas approximately one-third of patients were diagnosed with $\mathrm{AD}$ with concomitant stroke.

The clinical determinants of dementia that we identified fall into three categories: 1) stroke characteristics, including the severity and location of the presenting stroke, with more severe left hemisphere infarcts in the anterior and posterior cerebral artery territories of greatest importance; 2) vascular risk factors, including diabetes mellitus and prior stroke; and 3) host characteristics, including older age, fewer years of education, and nonwhite race/ethnicity. Patients who were recruited but did not undergo the 3-month poststroke dementia assessment more frequently had a history of myocardial infarction and congestive heart failure than patients who were examined, however, suggesting that our study may have failed to recognize an association between those disorders and dementia because they were underrepresented in our sample.

Numerous studies have investigated vascular dementia in community-based samples, dementia clinics, and autopsy series, ${ }^{22}$ but different methods of recruitment, assessment, and dementia diagnosis can result in wide variability in both the prevalence estimates and the clinical determinants that are reported. ${ }^{23-25}$ Thus, the few prior epidemiologic studies of the frequency and determinants of dementia after stroke that have used methods similar to our own provide information that is most relevant to the current study. Pohjasvaara et al. ${ }^{25}$ recruited a cohort of patients between the ages of 55 and 85 years with acute ischemic stroke and assessed 451 of them for the presence of dementia 3 months after stroke. Consistent with our findings, they reported that $20.0 \%$ of those patients met DSM-III-R criteria for dementia, with $64.4 \%$ of those demented patients diagnosed with a stroke-related dementia. They later investigated the clinical determinants of dementia among the 337 members of their cohort who also underwent MRI of the brain. ${ }^{6}$ Logistic regression suggested that dementia was associated with a major dominant hemispheral syndrome (OR 5.0), a history of prior cerebrovascular disease (e.g., ischemic stroke, intracerebral hemorrhage, subarachnoid hemorrhage; OR 2.0), aphasia (OR 5.6), and 6 or fewer years of education (OR 1.1). That logistic model was essentially unchanged when patients with "mixed" dementia were excluded. Although we also found that more severe left hemisphere stroke syndromes were associated with dementia status in our cohort, aphasia was not related. This discrepancy with regard to the importance of aphasia may have resulted from differences between the studies in the methods that were used for the assessment and diagnosis of dementia. Pohjasvaara et al. did not require evidence of nonverbal memory impairment for the diagnosis of dementia in aphasic patients, for example, which may have contributed to the increased frequency of de- 
Table 5 Logistic models of the clinical determinants of dementia based on all patients (Model A) and patients with vascular dementia and nondemented patients (Model B)

\begin{tabular}{|c|c|c|}
\hline Variable & Model A, OR (95\% CI) & Model B, OR (95\% CI) \\
\hline$\geq 80$ vs $60-69$ y & $12.73(6.12-26.47)$ & $7.83(3.17-19.31)$ \\
\hline $70-79$ vs $60-69$ y & $3.86(2.12-7.04)$ & $3.07(1.47-6.38)$ \\
\hline \multicolumn{3}{|l|}{ Education } \\
\hline$\leq 8$ vs $\geq 13$ y & $4.07(1.70-9.76)$ & $3.62(1.21-10.85)$ \\
\hline \multicolumn{3}{|l|}{ Race } \\
\hline Black vs white & $2.65(1.28-5.51)$ & $1.69(0.69-4.13)$ \\
\hline Hispanic vs white & $3.09(1.42-6.71)$ & $2.53(0.99-6.46)$ \\
\hline Sex (male vs female) & $0.74(0.43-1.26)$ & $0.84(0.43-1.65)$ \\
\hline Major hemispheral syndrome & $3.05(1.62-5.77)$ & $3.44(1.55-7.62)$ \\
\hline \multicolumn{3}{|l|}{ Stroke location } \\
\hline Left hemisphere vs brainstem/cerebellum & $2.12(1.04-4.28)$ & $3.60(1.40-9.25)$ \\
\hline Right hemisphere vs brainstem/cerebellum & $1.80(0.90-3.62)$ & $2.67(1.02-7.01)$ \\
\hline Vascular territory (ACA and PCA vs other) & $1.71(0.89-3.28)$ & $1.75(0.78-3.89)$ \\
\hline \multicolumn{3}{|l|}{ Stroke mechanism } \\
\hline Large artery atherosclerosis vs unknown/other & & $3.27(1.27-8.37)$ \\
\hline Cardiac embolism vs unknown/other & & $1.29(0.46-3.62)$ \\
\hline Lacunar vs unknown/other & & $2.43(0.97-6.06)$ \\
\hline
\end{tabular}

$\mathrm{ACA}=$ anterior cerebral artery; $\mathrm{OR}=$ odds ratio; $\mathrm{PCA}=$ posterior cerebral artery.

mentia that they found among those patients in their study.

Censori et $a .^{26}$ performed a similar study on a more highly selected sample of ischemic stroke patients. Among other criteria, they required that patients be between the ages of 40 and 79 and have no history of prior stroke or pre-existing dementia. Patients underwent dementia assessments 3 months after stroke, with the diagnosis based on NINDSAIREN criteria. ${ }^{20}$ Censori et al. found that 15 of 110 patients $(13.6 \%)$ met dementia criteria. They could not perform a formal multivariate analysis because of a lack of statistical power, but univariate analyses suggested that dementia was associated with clinical features including left hemisphere infarction, total anterior circulation infarcts, stroke severity, aphasia, diabetes mellitus, and atrial fibrillation. Although the frequency of dementia that Censori et al. reported was notably lower than that recognized in our study, most likely resulting from their recruitment of a younger sample that was free from prior stroke and pre-existing dementia, their univariate findings are compatible with our own.

Regarding stroke as a pathophysiologic basis for dementia, we found that more severe hemispheral syndromes as well as infarcts in the left hemisphere and regions supplied by the anterior and posterior cerebral arteries, such as the medial frontal and medial temporal lobes, were relevant. Although it is not surprising that more severe strokes would be associated with dementia, the role of infarct location is worthy of comment. It has been suggested that the left hemisphere is dominant for not only language but generalized cognitive function, and the results of our study and others ${ }^{6,26-28}$ support that hypothesis. Studies focusing specifically on the consequences of left hemisphere infarction suggest that even mild aphasia is associated with deficits in verbal memory $^{29}$ and intelligence. ${ }^{30}$ The involvement of limbic structures among stroke patients with dementia is consistent with the hypothesis that the medial frontal and medial temporal lobes are critical components of a network subserving memory. ${ }^{31} \mathrm{We}$ also found that lacunar and atherothrombotic stroke subtypes were most frequent among patients with vascular dementia. Small, strategically located lesions typically result from a lacunar stroke mechanism and tend to produce effects remote from and disproportionate to their size ${ }^{32}$ particularly with regard to the metabolic functioning of limbic structures. ${ }^{33}$

Regarding vascular risk factors, we found that diabetes mellitus was associated with dementia, consistent with the findings of Censori et al. ${ }^{26}$ Diabetes mellitus may affect cognitive function through its 
effects on cerebral blood flow, ${ }^{34}$ particularly with regard to reactivity ${ }^{35}$ and autoregulation, ${ }^{36}$ or by serving as a risk factor for clinically "silent" brain infarction. ${ }^{37,38}$ Consistent with the concept of "multiinfarct dementia," 4 we also noted that prior stroke was related to dementia, suggesting that the cumulative burden of cerebrovascular lesions is of importance. That cumulative burden could result from the number of such lesions, with multiple strategically located infarcts causing cognitive impairment and cognitive decline, the total volume of such lesions, or both characteristics.

Finally, certain host characteristics were relevant to dementia in our study, specifically older age, fewer years of education, and nonwhite race/ethnicity. Older age is likely to have served as a surrogate for concomitant $\mathrm{AD}$ in our primary logistic regression analysis, as suggested by a comparison of the models presented in table 5 , which shows that the odds ratios for the older age groups were reduced when patients with clinically diagnosed $\mathrm{AD}$ were excluded from the analysis. In a relevant study, Hénon et al. ${ }^{39}$ investigated the frequency of preexisting dementia in 202 stroke patients using an informantbased questionnaire and found that $16.3 \%$ of those patients were demented before stroke onset, suggesting that pre-existing $\mathrm{AD}$ may be an important contributor to poststroke dementia. Although the association between fewer years of education and dementia in our study could be an artifact of inherently poor test performance among patients who were simply less well educated, it also could reflect a greater cognitive reserve, ${ }^{40}$ and, thus, a greater ability to remain functionally competent despite an increasing burden of cerebrovascular disease among patients with more education. The association between nonwhite race/ethnicity and dementia is intriguing, and our study is unique in its ability to recognize that association because of the composition of the community in which Columbia-Presbyterian Medical Center is based. Race/ethnicity could be serving as a surrogate for variables that were unavailable for our analyses, including quality and not simply quantity of education and access to and quality of health care.

Our study has certain limitations. First, we did not have pathologic confirmation of the dementia subtype in our patients. Thus, it is possible that we underenumerated the frequency of concomitant $\mathrm{AD}$ among patients whom we diagnosed with probable vascular dementia. Our final logistic model was modified in two important ways when we excluded patients with clinically diagnosed $\mathrm{AD}$ from the analysis, however, with the odds ratios for all vascular variables increasing and the odds ratios for the older age groups decreasing, providing indirect support for the validity of our method of determining the dementia subtype. Second, although it was our intention to focus on the clinical determinants of dementia after stroke, we recognize that certain quantitative brain imaging measures would be likely to be relevant to dementia status in a multivariate model. ${ }^{27,28}$ It is possible that clinical variables such as a major hemispheral stroke syndrome and age served as surrogates for brain imaging variables such as the total volume of infarction and cerebral atrophy in our analyses, however, suggesting that the importance of the former variables may have been overestimated while we may have accounted at least in part for the effects of the latter variables. Third, although we recognized that certain host characteristics were associated with dementia status, we did not examine the contribution of genetic factors. Genetic factors are becoming important in vascular dementia research, whether as risk markers, such as the $A P O E-\epsilon 4$ allele, ${ }^{41}$ or primary independent risk factors, such as Notch3 mutations in cerebral autosomal dominant arteriopathy with subcortical infarcts and leukoencephalopathy. ${ }^{42,43}$

\section{Acknowledgment}

This article is dedicated to the late Thomas K. Tatemichi, MD, without whose efforts this work would not have been possible. The authors thank Richard Mayeux, MD, and Barry Gurland, MD, who provided helpful comments on this manuscript. The authors also thank Kim Morel-Betances, Norman Garcia, Melissa Diaz, and Clara Leon for their assistance with data collection, and Anthony Mayo for his work as project coordinator during the second phase of this project.

\section{References}

1. Binswanger O. Die Abgrenzung der allgemeinen progressiven Paralyse. Berl Klin Wochenschr 1894;31:1103-1105, 11371139, 1180-1186.

2. Alzheimer A. Die arteriosklertische Atrophie des Gehirns. Allg Zeitschr Psychiatr 1895;51:809-812.

3. Tomlinson BE, Blessed G, Roth M. Observations on the brains of demented old people. J Neurol Sci 1970;11:205-242.

4. Hachinski VC, Lassen NA, Marshall J. Multi-infarct dementia: a cause of mental deterioration in the elderly. Lancet 1974;ii:207-210.

5. Tatemichi TK, Desmond DW, Paik M, et al. Clinical determinants of dementia related to stroke. Ann Neurol 1993;33:568575.

6. Pohjasvaara T, Erkinjuntti T, Ylikoski R, Hietanen M, Vataja $\mathrm{R}$, Kaste M. Clinical determinants of poststroke dementia. Stroke 1998;29:75-81.

7. Gearing M, Mirra SS, Hedreen JC, Sumi SM, Hansen LA, Heyman A. The Consortium to Establish a Registry for Alzheimer's Disease (CERAD). Part X: Neuropathology confirmation of the clinical diagnosis of Alzheimer's disease. Neurology 1995;45:461-466.

8. Bowler JV, Munoz DG, Merskey H, Hachinski V. Fallacies in the pathological confirmation of the diagnosis of Alzheimer's disease. J Neurol Neurosurg Psychiatry 1998;64:18-24.

9. Snowdon DA, Greiner LH, Mortimer JA, Riley KP, Greiner PA, Markesbery WR. Brain infarction and the clinical expression of Alzheimer disease: the Nun Study. JAMA 1997;277: 813-817.

10. Heyman A, Fillenbaum GG, Welsh-Bohmer KA, et al. Cerebral infarcts in patients with autopsy-proven Alzheimer's disease, CERAD: part XVIII. Neurology 1998;51:159-162.

11. Tatemichi TK, Desmond DW, Mayeux R, et al. Dementia after stroke: baseline frequency, risks, and clinical features in a hospitalized cohort. Neurology 1992;42:1185-1193.

12. Goodglass H, Kaplan E. The assessment of aphasia and related disorders. 2nd ed. Philadelphia: Lea \& Febiger, 1983.

13. Folstein MF, Folstein SE, McHugh PR. "Mini-mental state": a practical method for grading the cognitive state of patients for the clinician. J Psychiatr Res 1975;12:189-198.

14. Mahoney FI, Barthel DW. Functional evaluation: the Barthel Index. Md Med J 1965;14:61-65. 
15. Blessed G, Tomlinson BE, Roth M. The association between quantitative measures of dementia and of senile change in the cerebral grey matter of elderly subjects. Br J Psychiatry 1968; 114:797-811.

16. Foulkes MA, Wolf PA, Price TR, Mohr JP, Hier DB. The Stroke Data Bank: design, methods, and baseline characteristics. Stroke 1988;19:547-554.

17. Williams JBW. A structured interview guide for the Hamilton Depression Rating Scale. Arch Gen Psychiatry 1988;45:742747.

18. Stern Y, Andrews H, Pittman J, et al. Diagnosis of dementia in a heterogeneous population: development of a neuropsychological paradigm-based diagnosis of dementia and quantified correction for the effects of education. Arch Neurol 1992;49: 453-460.

19. American Psychiatric Association. Diagnostic and statistical manual of mental disorders. 3rd ed., revised. Washington, DC: American Psychiatric Association, 1987.

20. Román GC, Tatemichi TK, Erkinjuntti T, et al. Vascular dementia: diagnostic criteria for research studies. Report of the NINDS-AIREN International Workshop. Neurology 1993;43: 250-260.

21. Desmond DW, Bagiella E, Moroney JT, Stern Y. The effect of patient attrition on estimates of the frequency of dementia following stroke. Arch Neurol 1998;55:390-394.

22. Desmond DW. Vascular dementia: a construct in evolution. Cerebrovasc Brain Metab Rev 1996;8:296-325.

23. Erkinjuntti T, Ostbye T, Steenhuis R, Hachinski V. The effect of different diagnostic criteria on the prevalence of dementia. N Engl J Med 1997;337:1667-1674.

24. Desmond DW, Moroney JT, Bagiella E, Sano M, Stern Y. Dementia as a predictor of adverse outcomes following stroke: an evaluation of diagnostic methods. Stroke 1998;29:69-74.

25. Pohjasvaara T, Erkinjuntti T, Vataja R, Kaste M. Dementia three months after stroke: baseline frequency and effect of different definitions of dementia in the Helsinki Stroke Aging Memory Study (SAM) cohort. Stroke 1997;28:785-792.

26. Censori B, Manara O, Agostinis C, et al. Dementia after first stroke. Stroke 1996;27:1205-1210.

27. Gorelick PB, Chatterjee A, Patel D, et al. Cranial computed tomographic observations in multi-infarct dementia: a controlled study. Stroke 1992;23:804-811.

28. Liu CK, Miller BL, Cummings JL, et al. A quantitative MRI study of vascular dementia. Neurology 1992;42:138-143.
29. Ween JE, Verfaellie M, Alexander MP. Verbal memory function in mild aphasia. Neurology 1996;47:795-801.

30. Basso A, Capitani E, Luzzatti C, Spinnler H. Intelligence and left hemisphere disease: the role of aphasia, apraxia and size of lesion. Brain 1981;104:721-734.

31. Mesulam MM. Large-scale neurocognitive networks and distributed processing for attention, language, and memory. Ann Neurol 1990;28:597-613.

32. Tatemichi TK, Desmond DW, Prohovnik I. Strategic infarcts in vascular dementia: a clinical and brain imaging experience. Drug Research 1995;45:371-385.

33. Tatemichi TK, Desmond DW, Prohovnik I, et al. Confusion and memory loss from capsular genu infarction: a thalamocortical disconnection syndrome? Neurology 1992;42:1966-1979.

34. Mankovsky BN, Metzger BE, Molitch ME, Biller J Cerebrovascular disorders in patients with diabetes mellitus. J Diabetes Complications 1996;10:228-242.

35. Griffith DNW, Saimbi S, Lewis C, Tolfree S, Betteridge DJ. Abnormal cerebrovascular carbon dioxide reactivity in people with diabetes. Diabet Med 1987;4:217-220.

36. Dandona P, James IM, Woollard ML, Newbury P, Beckett AG. Instability of cerebral blood-flow in insulin-dependent diabetics. Lancet 1979;ii:1203-1205.

37. Kase CS, Wolf PA, Chodosh EH, et al. Prevalence of silent stroke in patients presenting with initial stroke: the Framingham Study. Stroke 1989;20:850-852.

38. Kobayashi S, Okada K, Koide H, Bokura H, Yamaguchi S. Subcortical silent brain infarction as a risk factor for clinical stroke. Stroke 1997;28:1932-1939.

39. Hénon H, Pasquier F, Durieu I, et al. Preexisting dementia in stroke patients: baseline frequency, associated factors, and outcome. Stroke 1997;28:2429-2436.

40. Stern Y, Alexander GE, Prohovnik I, Mayeux R. Inverse relationship between education and parietotemporal perfusion deficit in Alzheimer's disease. Ann Neurol 1992;32:371-375.

41. Slooter AJC, Tang MX, van Duijn CM, et al. Apolipoprotein E $\epsilon 4$ and the risk of dementia with stroke: a population-based investigation. JAMA 1997;277:818-821.

42. Joutel A, Corpechot C, Ducros A, et al. Notch3 mutations in CADASIL, a hereditary adult-onset condition causing stroke and dementia. Nature 1996;383:707-710.

43. Desmond DW, Moroney JT, Lynch T, et al. CADASIL in a North American family: clinical, pathologic, and radiologic findings. Neurology 1998;51:844-849. 


\section{Neurology}

\section{Frequency and clinical determinants of dementia after ischemic stroke}

D.W. Desmond, J.T. Moroney, M.C. Paik, et al.

Neurology 2000;54;1124-1131

DOI 10.1212/WNL.54.5.1124

\section{This information is current as of March 14, 2000}

\section{Updated Information \&} Services

References

Citations

Permissions \& Licensing

Reprints including high resolution figures, can be found at: http://www.neurology.org/content/54/5/1124.full.html

This article cites 39 articles, 20 of which you can access for free at: http://www.neurology.org/content/54/5/1124.full.html\#\#ref-list-1

This article has been cited by 29 HighWire-hosted articles: http://www.neurology.org/content/54/5/1124.full.html\#\#otherarticles

Information about reproducing this article in parts (figures,tables) or in its entirety can be found online at:

http://www.neurology.org/misc/about.xhtml\#permissions

Information about ordering reprints can be found online:

http://www.neurology.org/misc/addir.xhtml\#reprintsus

Neurology ${ }^{\circledR}$ is the official journal of the American Academy of Neurology. Published continuously since 1951, it is now a weekly with 48 issues per year. Copyright . All rights reserved. Print ISSN: 0028-3878. Online ISSN: 1526-632X.

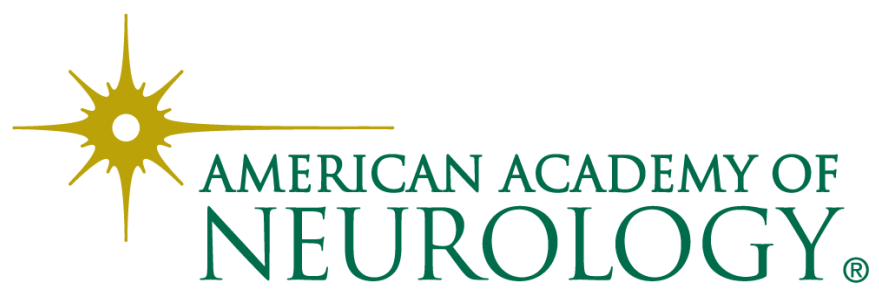

